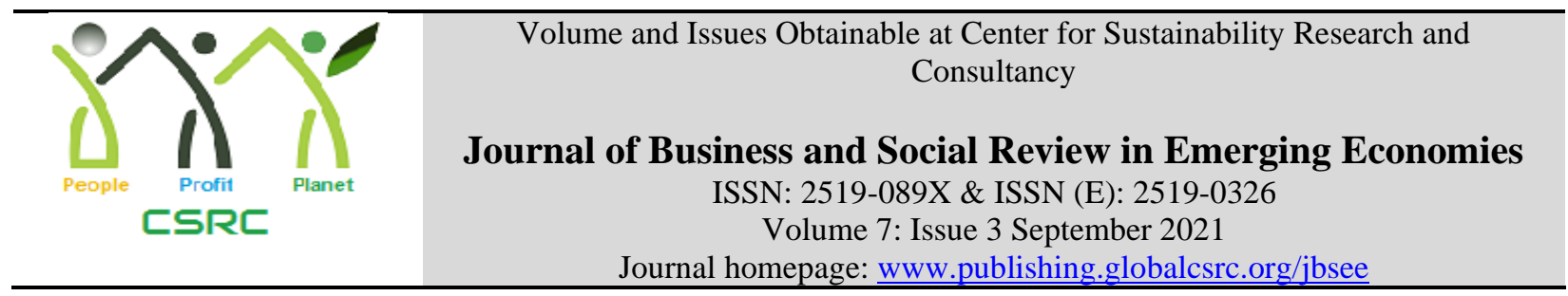

\title{
The Relationship between Employee Attitude Toward Change and Organizational Commitment: The Moderating Role of Psychological Defense Mechanisms
}

\begin{abstract}
*Saira Irfan, Department of Applied Psychology, University of Sahiwal, Pakistan
Rizwana Amin, Department of Professional Psychology, Bahria University, Islamabad, Pakistan

Umbreen Khizar, Department of Psychology, Institute of southern Punjab, Multan, Pakistan

Wizra Saeed, Department of Professional Psychology, Bahria University, Islamabad, Pakistan
\end{abstract}

*Corresponding author's email: sairairfan@uosahiwal.edu.pk

\section{ARTICLE DETAILS \\ History \\ Revised format: Aug 2021 \\ Available Online: Sep 2021}

\section{Keywords}

Defense Mechanisms,

Attitude Toward Change,

Organizational

Commitment,

Organizational Change.

\section{JEL Classification}

$M 1, M 2$

\begin{abstract}
Purpose: The purpose of this research was to determine which defense mechanisms can help to regulate the link between attitude toward change and organizational commitment. Psychological defenses are characterized as protective processes that help individuals maintain their integrity in the face of threat and danger. Previously, extant research has mainly emphasized organizational issues while individual psychological factors have remained largely ignored. Therefore, this paper seeks to investigate the moderating effects of psychological defense mechanisms on the relationship between employee attitude toward change and organizational commitment.
\end{abstract}

Design/Methodology/Approach: A total of 499 employees were chosen from the banks of the Southern Punjab, Pakistan, using a purposive sampling methodology. The information was gathered using validated questionnaires. The data was analyzed for descriptive statistics, correlation, and hierarchical multiple regression analysis.

Findings: The findings showed a positive correlation between employee positive attitude toward change and organizational commitment and a negative relationship between employee negative attitude toward change and organizational commitment. The results of the moderation analysis revealed that the association between employee attitude toward change and organizational commitment is negatively moderated by all three defense mechanisms.

Implications/Originality/Value: The findings highlight the significance of psychological factors during the organizational change process and suggests recruiting employees with positive attitudes.

Recommended citation: Irfan, S., Amin, R., Khizer, U., and Saeed, W. (2021). The Relationship between Employee Attitude Toward Change and Organizational Commitment: The Moderating Role of Psychological Defense Mechanisms. Journal of Business and Social Review in Emerging Economies, 7 (3), 761-772. 


\section{Introduction}

Organizational change has been regarded as a vital aspect of the organizational life cycle to stay up with the present changing and challenging business environment. Organizations such as banks are compelled to respond efficiently to internal and external forces such as globalization, business change, the changing world economy, and enormous technical breakthroughs to survive and expand in the marketplace (Gelaidan et al., 2016). The banking sector, whose primary goal is to provide services to clients, plays a significant role in today's society. Because of increased competition, the management of banks has become increasingly complex and challenging. As a result, some modifications to various parts of bank management are required to ensure the bank's continued survival and success. To effectively manage change, the bank must continue to improve and develop solutions to deal with it. Today, the most crucial duty for managers is to lead change (Gotsill \& Meryl, 2007). Therefore, organizations constantly attempt to make changes for survival, growth, and competition (Battilana et al., 2010). However, 70 percent of major change initiatives are unsuccessful due to resistance (Vakola, 2014) and employees' negative attitudes about change (Bellou, 2007; Coetsee, 1999; Durmaz, 2007). Employees play a critical role during the change process, not only in terms of infrastructure and working methods but also in mentality shifts (Gladwell, 2000).

Thus, employees' attitudes regarding change are critical in determining whether a company's change efforts succeed or fail. However, incessant change in the workplace often breeds ambiguity and dread about an organization's future direction, as well as an employee's prospects and status within it. Both of which have been shown to have a negative impact on employees' work experience, attitudes, and performance (Lysova et al., 2015; Coetzee \& Chetty, 2015; Cullen et al., 2014).

Besides, change also leads to increased stress and uncertainty between employees and management, and a decrease in organizational commitment (Coetsee, 1999). Antoni (2004) stated that to enable sustainable organizational change, one must influence the beliefs of employees, which form their behaviors. As a result of a strong, positive attitude toward change, employees show persistence, motivation, and determination that promote and aid the change endeavor. Similarly, Porras and Robertson (1992) stated that behavioral change is critical to organizational change at the individual employee level. Individuals' unconscious processes emerge in response to risks of change (Halton, 1994; O'Connor, 1993). They utilize mature and customary defense mechanisms to guard against change and anxiety (Oldham \& Kleiner, 1990; de Board, 1978). Such defenses can restrict and impair their ability to adjust to change (Halton, 1994). Individuals often desire an optimal level of stimulation and strive to sustain it (Nadler, 1981; Zaltman \& Duncan, 1977). People react differently to change (Carnall, 1986) because of individual differences in aptitude and desire to adjust to change (Darling, 1993). Some of them go quickly through change, while others get stuck or go through repeated shifts (Scott \& Jaffe, 1988). It may be claimed that most organizational change is handled technically and the influence of human aspects on the consequences of change is mostly ignored (Arendt, Landis \& Meister, 1995). Management finds it easy to concentrate their efforts on and focus on the technical side of change, such as formulating policies and action plans, evaluating efficiency, and optimizing assets (Bovey \& Hede, 2001; Huston, 1992).

Since human capital plays a key role in the success of change, failure is frequently the result of human nature and disapproval of change or due to the lack of employees' precise behavioral attributes necessary to adjust swiftly to new circumstances. Hence, the effectiveness of the change depends upon the organizational approach to treat employees during a change project.

Management must know the relationship between defense mechanisms and individual behavioral objectives while implementing significant change (Bovey \& Hede, 2001). It appears that 
determining how individual defense mechanisms play a role in organizational change is highly challenging for managers.

Psychological defense mechanisms have been linked to resistance to organizational change in previous studies (Cinite \& Duxbury, 2018; Barabasz, 2016; Bovey \& Hede, 2001; Craine, 2007). However, there is a dearth of research on the psychological processes that influence employees' attitudes about change and, consequently, organizational outcomes like organizational commitment. It will be easier to implement change if management successfully identifies and deals with the psychological defense mechanisms used by employees (Amarantou, 2018). As a result, the aim of the current study is to look at the relationship between employee attitude toward change and organizational commitment through psychological defense mechanisms.

\section{Theory and Hypotheses}

The conceptual basis for comprehending unconscious processes is provided by psychoanalytical theory. When discussing organizational change and managers' capacity to identify employee defense mechanisms that may become an issue, later on, this viewpoint can be quite useful. The mind's defense systems are its conscious and unconscious responses to anxiety-inducing experiences (Barabasz, 2016). Anxiety is important to all psychoanalytic theory because it is the most terrible feeling a human being can have when it is intense and acute (de Board, 1978). Regardless of the cause (real or imagined) anxiety produces the same biological reactions in a person. It occurs when the subconscious mind's usual thoughts, feelings, or behaviors clash with the conscious mind's different opinions, feelings, and plans of action (de Board, 1978). Unconscious drives tend to steer and redirect energy towards other things and ignore the change initiative (Oldham \& Kleiner, 1990). These defenses are considered the primary source of incompetence in employees and organizations, as well as a factor in resistance to organizational change (Bovey \& Hede, 2001). Resistance to or attitude toward organizational change is likely to be associated with a range of work outcomes, including job satisfaction and organizational commitment (Rush et al., 1995; Schweiger \& DeNisi, 1991). When addressing organizational change, managers and business owners must consider the potential stumbling blocks to particular areas of change. Therefore, the present study is embarked on to investigate the moderating effects of psychological defense mechanisms on employee attitudes toward change and organizational commitment.

\section{Attitude Toward Change and Organizational Commitment}

According to tri-dimensional concept, organizational commitment is an individual's level of identification with and involvement in a particular organization and has ramifications for the decision to stay or leave the organization. It is defined by three dimensions that are intertwined. A strong belief in and acceptance of the organization's goals and ideals; a readiness to put in a significant effort on behalf of the organization; and a strong desire to stay in the organization (Meyer \& Allen, 1991,1997; Mowday et al., 1979).

An employee's general favorable or unfavorable evaluative opinion about organizational change is characterized by their attitude toward organizational change (Lines, 2005). Affective, behavioral, and cognitive factors have a role in one's attitude toward change. These three elements represent three different ways in which people evaluate an object or situation (McGuire, 1985). The emotive element is concerned with one's feelings about change, such as being furious or apprehensive, whereas the cognitive component is concerned with an individual's perception of change, whether it is necessary or adventurous; and the behavioral component entails actions or the intent to behave in reaction to change. For example, criticizing the change and attempting to persuade others of its negative consequences. In this way, reactions to organizational changes can range from positive (it is necessary for organizational success) to negative (it will cause organizational failure) (Piderit, 2000). According 
to the organizational commitment theory, employees' commitment is contingent on their favorable attitude toward the organization or its goals (Liou, 2009; Mowday et al. 1979). Beliefs, perceptions, and attitudes are crucial in successful change, Armenakis et al. (1993). In order to achieve organizational goals and implement a successful change program, employees must have a positive attitude toward change (Eby et al., 2000).

Similarly, previous studies have also verified that positive attitudes toward change are linked to higher levels of commitment to an organization (Elias, 2009; Herscovitch \& Meyer, 2002; Jones \& Van de Ven, 2016), as well as higher ratings of that organization's effectiveness (Jones \& Van de Ven, 2016). Conversely, most employees with an unfavorable attitude toward change report criticism about their working conditions (Wanous et al., 2000). Negative attitudes towards change have long been thought to be an impediment to implementing change in the workplace (Henricks et al., 2020; Oreg, 2018; Kotter, 1996).

Numerous investigators (Salami, 2008; Akintayo, 2010; Wasiu, 2013) have reported that a large number of employees have a lower degree of organizational commitment. They concluded that the administration's awareness about employees' perception of change will help them prioritize useful measures to educate employees for organizational change (Liou, 2009; Mowday et al. 1979) and, consequently, increase commitment.

The following hypotheses are developed based on the reviewed literature:

H1. There is a significant positive relationship between employee attitudes toward change and organizational commitment.

H1a. There is a significant positive relationship between an employee positive attitude toward change and organizational commitment.

H1b. There is a significant negative relationship between an employee negative attitude toward change and organizational commitment.

\section{Psychological Defense Mechanisms as a Moderator}

To reduce undesirable psychological effects, particularly anxiety, individuals used to misrepresent perceptions of reality, according to the idea presented by Sigmund Freud (Kassin, 1998). Generally, these misrepresentations happen involuntarily. However, they may emerge consciously (Newman, 2001). Freud classified six key defense mechanisms that describe human behavior and reasoning. Other defense mechanisms have also been recognized in the literature. Individuals use these defense mechanisms to deal with anxiety inducing stimuli, which prevents them from anxiety. However, consistent use of these mechanisms may cause maladjustment (Freud, 1937).

There are three types of defense mechanisms: mature, immature and neurotic. Splitting, projection, and projective identification are examples of primary (neurotic) defense mechanisms. The mechanisms that emerge first are those that work on an unconscious level. They block adequate response to environmental stimuli to the greatest extent possible. Repression, reaction formation, denial, isolation, and undoing allow adaptability to reality's conditions and probable harm, but they produce less direct disruption to the effects of the task completed. Compensation, repression, anticipation, sublimation, and humor are classified as the most mature defense mechanisms, which aid in coping with harsh psychological realities. They effectively manage challenges and do not permit anxiety, shame, or other unwanted emotions to control the behavior of individuals. However, the control of immature defense mechanisms reduces the attributes of performance, and decisions, as well as the recommended solutions (Barabasz, 2016).

According to Coetsee (1999), the approbation of advancement (commitment) and opposition to change (resistance) are sometimes viewed as independent, distinct occurrences. However, they are practically synonymous in that they both denote an extreme, with each being on the inverse end of the continuum. Within the continuum, moving from resistance to commitment is accomplished 
through a series of stages. Employees go through a reaction phase when their workplace undergoes change. According to Scott and Jaffe (1988), the process includes four phases: early denial, resistance, incremental exploration, and ultimately commitment. Therefore, organizational commitment can be predicted using defense mechanisms. In this study, defense mechanisms are expected to moderate the relationship between employee attitude toward change and organizational commitment.

Based on the literature review, the following hypotheses are developed for testing.

H2. Defense mechanisms would moderate the relationship between employee attitudes toward change and organizational commitment.

H2a. Mature defense mechanisms would moderate the relationship between employee attitude toward change and organizational commitment.

H2b. Neurotic defense mechanisms would moderate the relationship between employee attitude toward change and organizational commitment.

H2c. Immature defense mechanisms would moderate the relationship between employee attitude toward change and organizational commitment.

Figure 1

Conceptual framework of the study.

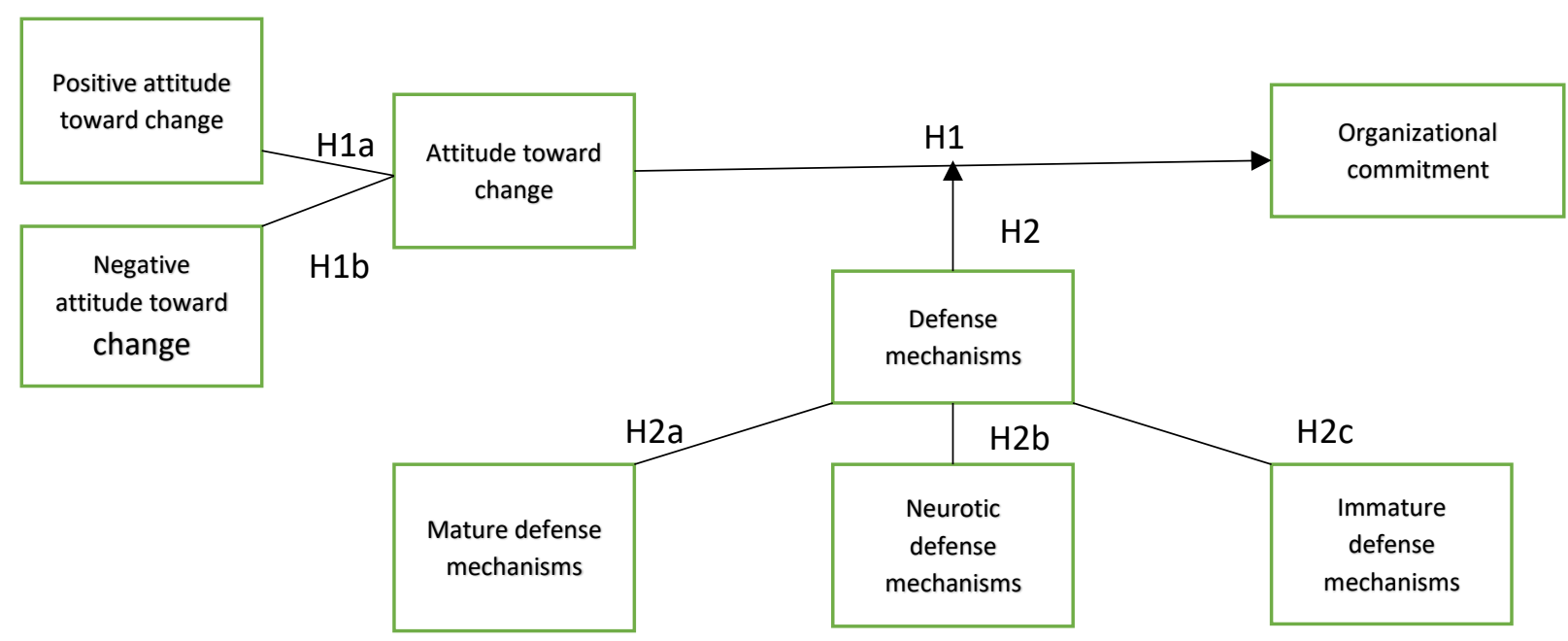

\section{Research Design and Method}

This is an exploratory study with a quantitative component. The participants were chosen through a purposive sampling method from the five leading banks in Southern Punjab, Pakistan (National Bank of Pakistan, Habib Bank, United Bank, Muslim Commercial Bank, and Allied Bank). Males made up 56.51 per cent of the participants, while females made up 43.49 per cent. Selfadministered questionnaires were used to collect data. The participants were given the option to engage in the study willingly. The researcher respected the privacy and confidentiality of the participants. The analysis was completed using the Statistical Package for Social Sciences (SPSS, version 21.0).

\section{Defense Style Questionnaire (DSQ-40)}

The DSQ-40 was used in this investigation (Andrews et al., 1993). Using a 9-point Likert scale, this questionnaire explores mature, immature, and neurotic defense mechanisms. The factor scores were computed by the average scores of the defense mechanisms that have a place with each variable, and the single defense score was measured by the average of the two questions for each defense. Reported Cronbach alpha coefficients ranged from .59 to .89. The Cronbach alpha coefficient in this study was .90 . 


\section{Attitude Toward Change Scale (ACQ)}

Attitude toward Change Scale developed by Vakola et al. (2004) was applied to assess attitudes toward change. There are 29 items on the scale. The questions were graded on a five-point Likert scale, with 1 indicating strong disagreement and 5 indicating strong agreement. The negative questions were flipped around. High scores reflect a positive attitude toward change in the workplace. The scale has a high level of internal consistency. The scale's alpha value is .92. The Cronbach alpha coefficient in this study was .83.

\section{Employee Commitment Survey}

The revised Employee Commitment Survey was used to assess organizational commitment (Meyer et al., 1993). This 18-item tool measures affective, normative, and continuous commitment, each with six items. The questions were graded on a seven-point Likert scale, on which 1 represented strongly disagree and 7 represented strongly agree. Midpoints were calculated solely on the basis of items that are significant to the scale. A high score indicates increased commitment. The overall reliability is greater than .79 (Meyer \& Allen, 1997). The Cronbach alpha coefficient in this study was .75.

\section{Results}

Data was analyzed for descriptive statistics, correlation and moderated multiple regression analysis.

Table 1

Means and Standard Deviations of the Variables

\begin{tabular}{lccc}
\hline \multicolumn{1}{c}{ Variables } & $\mathrm{N}$ & Mean & Std. Deviation \\
\hline Positive Attitude Toward Change & 499 & 3.3552 & .47495 \\
Negative Attitude Toward Change & 499 & 3.0846 & .73635 \\
Attitude Toward Change & 499 & 3.5713 & .57565 \\
Mature Defense Mechanisms & 499 & 5.9138 & 1.20937 \\
Neurotic Defense Mechanisms & 499 & 5.9687 & 1.20162 \\
Immature Defense Mechanisms & 499 & 5.6136 & 1.13120 \\
Organizational Commitment & 499 & 4.6956 & .62075 \\
\hline
\end{tabular}

Note: $* p<.05$

Table 1 presents the results of the descriptive analysis. All variables attained the above average mean.

Table 2

Pearson Correlation of Variables

\begin{tabular}{lccc}
\hline \multicolumn{1}{c}{ Scales } & 1 & 2 & 3 \\
\hline 1. Positive Attitude Toward Change & 1 & $.078^{*}$ & $.459^{* *}$ \\
2. Negative Attitude Toward Change & & 1 & -.029 \\
3. Organizational Commitment & & & 1 \\
\hline
\end{tabular}

Note: *p $<.05$

The results of the correlation for $\mathrm{H} 1 \mathrm{a}$ and $\mathrm{H} 1 \mathrm{~b}$ are presented in Table 2. These statistics show a positive correlation $(r=.459 * *)$ between employee positive attitude toward change and organizational commitment and a very week negative correlation $(r=-.029)$ between employee negative attitude toward change and organizational commitment.

Table 3

Moderated Multiple Regression Analysis

\begin{tabular}{lccccccc}
\hline \multicolumn{1}{c}{ Model } & $b$ & $S E$ & $\beta$ & $t$ & $p$ & Supported & $R^{2}$ \\
\hline ATOC $\rightarrow$ OC & .16 & .025 & .27 & 6.50 & .000 & Yes & .181 \\
MDM $\rightarrow$ OC & .19 & .026 & .27 & 7.17 & .000 & Yes & \\
MDM $^{*}$ ATOC $\rightarrow$ OC & -.05 & .02 & -.09 & -2.20 & .000 & Yes & .189 \\
\hline
\end{tabular}

Note: ATOC=Attitude toward change; MDM=Mature Defense Mechanisms; OC=Organizational Commitment The findings of the moderated regression analysis used to test $\mathrm{H} 2 \mathrm{a}$ are shown in Table 3 . The hypothesis was investigated using a technique called moderated multiple regression, which was described by Aiken and West (1991). The interaction term is statistically significant $(\beta=-.09$, 
$p<.05)$. As a result, hypothesis $2 \mathrm{a}$ is supported and shows negative moderation effects. The results demonstrate that the moderation effect of the mature defense mechanism weakens the positive relationship between attitude towards change and organizational commitment. The moderating effect of the mature defense mechanism has increased the value of $R^{2}$ from .181 to .189 for this model but this is a minimal change. However, it plays a significant role in testing the moderation effect.

Figure 2

Graphical representation of interaction among variables

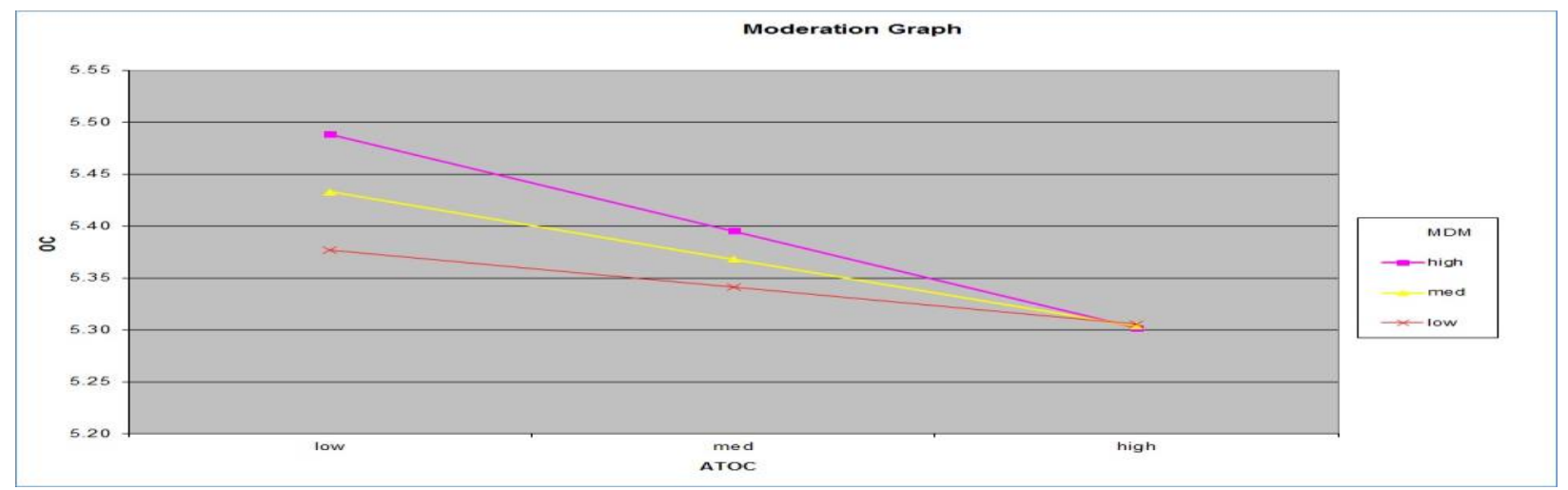

Table 4

Moderated Multiple Regression Analysis

\begin{tabular}{lccccccc}
\hline \multicolumn{1}{c}{ Model } & $B$ & $S E$ & $\beta$ & $t$ & $p$ & Supported & $R^{2}$ \\
\hline ATOC $\rightarrow$ OC & .17 & .025 & .27 & 6.79 & .000 & Yes & .197 \\
NDM $\rightarrow$ OC & .19 & .025 & .32 & 7.90 & .000 & Yes & Yes \\
NDM $^{*}$ ATOC $\rightarrow$ OC & -.06 & .026 & -.09 & -2.23 & .026 & .205 \\
\hline
\end{tabular}

Note: $\mathrm{ATOC}=$ Attitude toward change; $\mathrm{NDM}=$ Neurotic Defense Mechanisms; $\mathrm{OC}=$ Organizational Commitment The findings of the moderated regression analysis used to evaluate $\mathrm{H} 2 \mathrm{~b}$ are shown in Table 4. The link between employee attitude toward change and organizational commitment was negatively moderated by neurotic defense mechanisms. Based on results, the interaction term is significant $(\beta$ $=-.09, p<.05)$. As a result, hypothesis $2 \mathrm{~b}$ is supported. The results reveals that the moderation role, i.e., the neurotic defense mechanism, dampens or weakens the positive association between attitude towards change and organizational commitment. Due to the moderating effect of the neurotic defense mechanism, the $R^{2}$ value has increased from .197 to .205 but this is a minimal change. However, it plays a significant role in testing the moderation effect.

Figure 3

Graphical representation of interaction among variables.

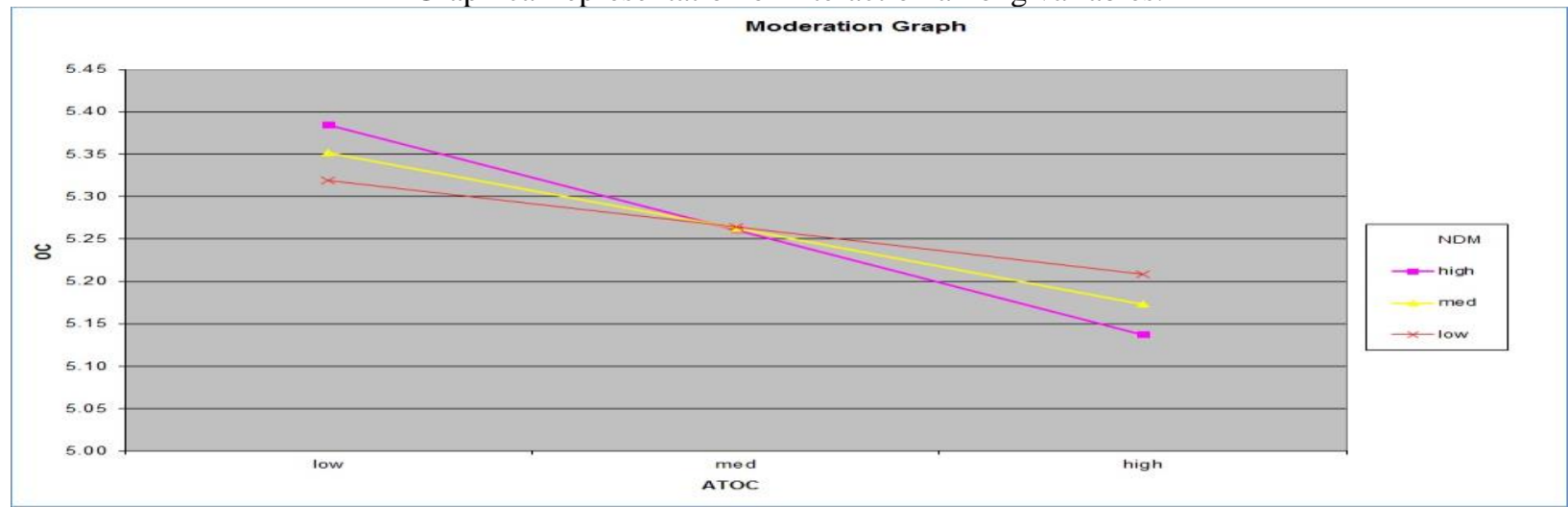

Table 5

Moderated Multiple Regression Analysis

\begin{tabular}{lccccccc}
\hline \multicolumn{1}{c}{ Model } & $B$ & $S E$ & $\beta$ & $t$ & $p$ & Supported & $R^{2}$ \\
\hline ATOC $\rightarrow$ OC & .19 & .026 & .30 & 7.02 & .000 & Yes & .176 \\
NDM $\rightarrow$ OC & .18 & .026 & .29 & 6.91 & .000 & Yes & \\
IDM*ATOC $\rightarrow$ OC & -.08 & .029 & -.12 & -2.86 & .004 & Yes & .189 \\
\hline
\end{tabular}


Note: ATOC=Attitude toward change; IDM=Immature Defense Mechanisms; OC= Organizational Commitment The results of the moderated regression analysis used to investigate $\mathrm{H} 2 \mathrm{c}$ are presented in Table 5. Immature defense mechanisms negatively moderated the association between employee attitude toward change and organizational commitment. The interaction term is significant $(\beta=-.12$, $p<.0005)$. As a result, hypothesis $2 \mathrm{c}$ is supported. The results indicate that the moderation effect of immature defense mechanisms weakens the positive relationship between employee attitude towards change and organizational commitment. Based on moderation results of the immature defense mechanism, there is increase in the $R^{2}$ value (i.e., from .176 to .189). This is a minimal change, but it is considered significant in testing the moderation effect.

Figure 4

Graphical representation of interaction among variables.

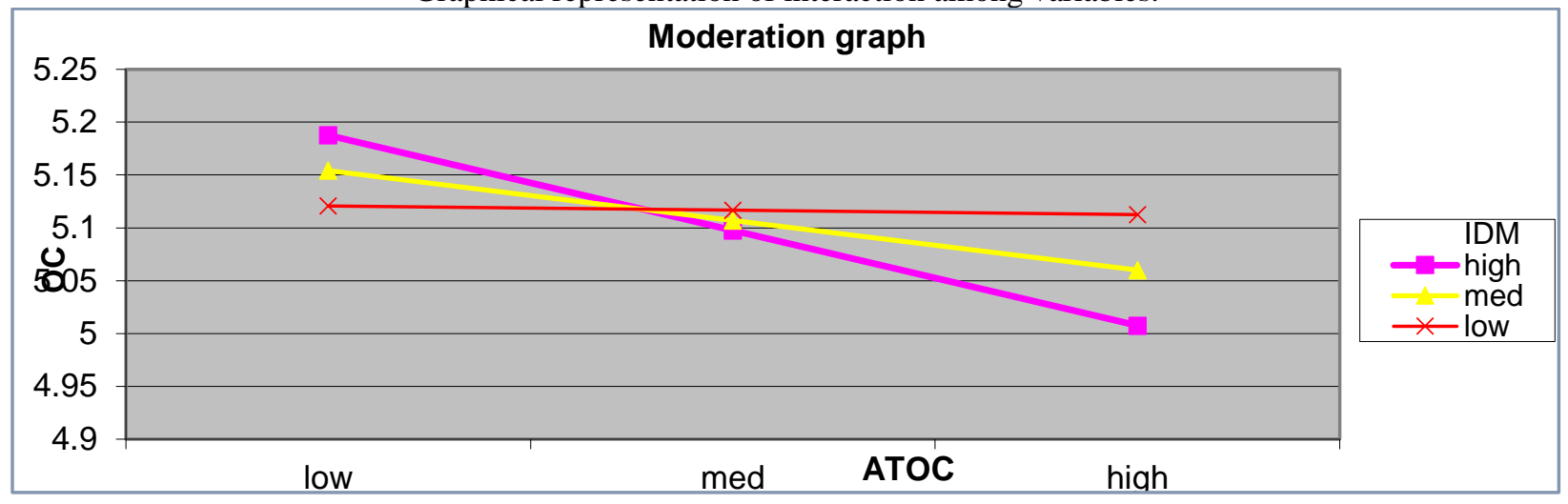

\section{Discussion}

This study's findings revealed a positive relationship between a positive attitude toward change and organizational commitment, as well as a vey week negative relationship between a negative attitude toward change and organizational commitment. These findings are in line with previous studies which reported that positive attitudes towards change have also been connected to higher levels of commitment to an organization (Jones \& Van de Ven, 2016). Besides, negative attitudes towards change have long been considered a barrier to change implementation in the workplace (Henricks et al., 2020; Oreg, 2018).

The findings of this revealed that at a significant or marginally significant level, the mature defense mechanisms were found to negatively moderate the link between employee attitudes toward change and organizational commitment. These findings are in line with a previous study that found a link between adaptive defense mechanisms and the desire to resist (Bovey \& Hede, 2001).

Findings also showed that the neurotic defense mechanisms negatively moderated the relationship between employee attitude toward change and organizational commitment. Neurotic defenses that transform negative emotions into positive ones (reaction formation), the change agent into a good one (e.g., idealization), or the negative consequences of change into neutral ones (e.g., undoing) may be inefficient responses to change-induced anxiety. Neurotic people have a proclivity for denying unpleasant realities and suppressing undesirable thoughts (Punamaki et al., 2002).

Findings also revealed that immature defense mechanisms negatively moderate the relationship between employee attitude toward change and organizational commitment. To guard against the most terrible conditions, an immature defense mechanism incorporates a multitude of defense mechanisms, such as projection and displacement, as well as splitting and dissociation. Employees with an immature defense mechanism may be protected from the negative effects of high levels of anxiety (Fischer \& Ayoub, 1995).

Based on the findings it is concluded that the participants in this study viewed their anxiety as uncontrollable, leading them to develop defense mechanisms to cope with it. The change process 
increases anxiety levels, and people are more prone to using defense mechanisms, whether mature, immature, neurotic, or a mixture of all three. In the present study, immature defense mechanisms' moderating effects were more significant in reducing organizational commitment in relation to employee attitudes toward change. These findings can be attributed to the fact that although these defense mechanisms enable employees to manage undesirable emotions, in the long run, they have a negative impact on the organizational environment and work outcomes (Barabasz, 2016), such as organizational commitment. Therefore, this paper highlights the significance of psychological defense mechanisms in the face of change.

\section{Practical Implications}

When implementing change, Kotter and Schlesinger (1979) suggested that it is critical to assess human resistance. Similarly, according to Olson (1990), in order to promote organizational change, it is sometimes necessary to understand the unconscious motives to accomplish successful change endeavor. Management should acknowledge the benefits of working with the human dimension and devise suitable intervention techniques while implementing big change.

\section{Limitations and Suggestions}

Nonetheless, the study is not devoid of limitations. Firstly, it is a country specific study. It is suggested to extend this study to cross-sector and culture as well, since this would reveal the crosscultural effects of this model. The role of individual defense mechanisms in relation to other variables was not investigated, which may provide in-depth information about an employee unconscious motive. It is also suggested to explore the moderating effects of individual defense mechanisms and gender in this relationship. The current study's cross-sectional research style, as opposed to a longitudinal or experimental methodology, does not allow for causal explanations. The use of self-reported measures is a drawback of this study. The use of self-reports raises the risk of common method bias.

\section{Conclusion}

In conclusion, the possibility to identify the defense mechanisms used by the employees will positively regulate the activities connected with the successful execution of organizational change. It will also minimize the unfavorable outcomes of the employees' maladjusted behaviors in the organization.

\section{References}

Aiken, L. S., \& West, S. G. (1991). Multiple regression: Testing and interpreting interactions. Sage.

Akintayo, D. I. (2010). Work-family role conflict and organizational commitment among industrial workers in Nigeria. Journal of Psychology and Counselling, 2(1), 1-8. Retrieved from https://citeseerx.ist.psu.edu/viewdoc/download?doi=10.1.1.853.3656\&rep=rep1\&type=p df

Amarantou, V., Kazakopoulou, S., Chatzoudes, D., \& Chatzoglou, P. (2018). Resistance to change: An empirical investigation of its antecedents. Journal of Organizational Change Management, 31(2), 426-450. https://doi.org/10.1108/JOCM-05-2017-0196

Andrews, G., Singh, M. \& Bond, M. (1993). The defense style questionnaire. The Journal of Nervous and Mental Disease, 181 (4), 246-56. https://doi.org/10.1097/00005053199304000-00006

Antoni, C. H. (2004). Research note: A motivational perspective on change processes and outcomes. European Journal of Work and Organizational Psychology, 13(2), 197-216. https://doi.org/10.1080/13594320444000065

Arendt, C.H., Landis, R.M. \& Meister, T.B. (1995). The human side of change - part 4. 
IEESolutions, 22-6.

Armenakis, A. A., Harris, S. G., \& Mossholder, K. W. (1993). Creating readiness for organizational change. Human Relations, 46(6), 681-703.

https://doi.org/10.1177/001872679304600601

Bovey, W., \& Hede, A. (2001). Resistance to organizational change: The role of cognitive and affective processes. Leadership \& Organizational Development Journal, 22(1), 116-118. https://doi.org/10.1108/01437730110410099

Barabasz, A. (2016). Psychodynamic perspective of organizational change. Management, 20(1), 155-166. https://doi.org/10.1515/manment-2015-0031

Battilana, J., Gilmartin, M., Sengul, M., Pache, A.C., \& Alexander, J. A. (2010). Leadership competencies for implementing planned organizational change. The

Leadership Quarterly, 21(3), 422-438. https://doi:10.1016/j.leaqua.2010.03.007

Bellou, V. (2007). Psychological contract assessment after a major organizational change: The case of mergers and acquisitions. Employee Relations, 29(1), 68-88. https://doi.org/10.1108/01425450710714487

Bovey, W. H., \& Hede, A. (2001). Resistance to organizational change: The role of defense mechanisms. Journal of Managerial Psychology, 16(7), 534-548. https://doi.org/10.1108/EUM0000000006166

Carnall, C. A. (1986), Toward a theory for the evaluation of organizational change. Human Relations, 39(8), 745-766. https://doi.org/10.1177\%2F001872678603900803

Cinite, I., \& Duxbury, L. E. (2018). Measuring the behavioral properties of commitment and resistance to organizational change. Journal of Applied Behavioral Science, 54(2), 113 139. https://doi.org/10.1177/0021886318757997

Coetzee, M., \& Chetty, P. J. J. (2015). Job stress and attitudes toward change: The mediating effect of psychological attachment. Journal of Psychology in Africa, 25(6), 528-536. https://doi.org/10.1080/14330237.2015.1124605

Coetsee, L. (1999). From resistance to commitment. Public Administration Quarterly, 23, 204222. Retrieved from https://www.jstor.org/stable/40861780

Craine, K. (2007). Managing the cycle of change. Information Management Journal, 41(5), 4449.

Cullen, K. L., Edwards, B. D., Casper, W. C., \& Gue, K. R. (2014). Employees' adaptability and perceptions of change related uncertainty: Implications for perceived organizational support, job satisfaction and performance. Journal of Business and Psychology, 29(2), 269-280. http:// doi.org/10 1007/s10869-013-9312-y

Darling, P. (1993). Getting results: The trainer's skills. Management Development Review, 6(5), 25-9. https://doi.org/10.1108/EUM0000000000757

De Board, R. (1978), The Psychoanalysis of Organizations. London, Routledge.

Durmaz, H. (2007). Officer attitude toward organizational change in the Turkish National Police (Doctoral dissertation, University of North Texas). Retrieved from digital.library.unt.edu/ark:/67531/metadc3977/m2/.../dissertation.

Eby, L. T., Adams, D. M., Russell, J. E., \& Gaby, S. H. (2000). Perceptions of organizational readiness for change: Factors related to employees' reactions to the implementation of team-based selling. Human relations, 53(3), 419-442. http:// doi.org $/ 10.1177 / 0018726700533006$

Elias, S. M. (2009). Employee commitment in times of change: Assessing the importance of attitudes toward organizational change. Journal of Management, 35(1), 37-55. https://doi.org/10.1177/ 0149206307308910

Freud, A. (1937). The Ego and the Mechanisms of Defense. Hogarth Press and Institute of PsychoAnalysis

Gelaidan, H. M., Al-Swidi, A., \& Mabkhot, H. A. (2016). Employee readiness for change in public higher education institutions: Examining the joint effect of leadership behavior and emotional intelligence. International Journal of Public Administration, 41(2), 150- 
158. https://doi.org/10.1080/01900692.2016.1255962

Gladwell, M. (2000). The tipping point: How little things can make a big difference. Little, Brown and Company.

Gotsill, G., \& Meryl, N. (2007). From resistance to acceptance. How to implement change management. Exel Publication.

Halton, W. (1994). Some unconscious aspects of organizational life: Contributions from psychoanalysis. In A. Obholzer, \& V. Z. Roberts (Eds.). The Unconscious at Work (PP. 11-18). Routledge.

Henricks, M. D., Young, M., \& Kehoe, E. J. (2020). Attitudes toward change and transformational leadership: A longitudinal study. Journal of Change Management, 20(3), 202-219. https://doi.org/10.1080/14697017.2020.1758529

Herscovitch, L., \& Meyer, J. P. (2002). Commitment to organizational change: Extension of a three-component model. Journal of Applied Psychology, 87(3), 474-487. https://doi.org/10.1037/0021- 9010.87.3.474

Huston, L.A. (1992). Using total quality to put strategic intent into motion. Planning Review,20(5), 21-3. https://doi.org/10.1108/eb054373

Jones, S. L., \& Van de Ven, A. H. (2016). The changing nature of change resistance: An examination of the moderating impact of time. Journal of Applied Behavioral Science, 52(4), 482-506. https://doi.org/10.1177/0021886316671409

Kassin, S. (1998). Psychology (2nd ed.). Prentice-Hall.

Kotter, J. P. \& Schlesinger, L. A. (1979). Choosing strategies for change. Harvard Business Review, 57(2). 106-14. https://doi.org/10.1007/978-1-349-20317-8_21

Lines R. (2005). How social accounts and participation during change affect organizational learning. Journal of Workplace Learning, 17 (3), 157-177. https://doi.org/10.1108/13665620510588680

Liou, S. R. (2009). Nurses' intention to leave: Critically analyse the theory of reasoned action and organizational commitment model. Journal of Nursing Management, 17(1), 92-99. https://doi.org/10.1111/j.1365-2834.2008.00873.x

Lysova, E. I., Richardson, J., Khapova, S. N., \& Jansen, P. G.W. (2015). Change-supportive employee behavior: A career identity explanation. Career Development International, 20(1), 38-62. http://doi org/10.1108/CDI-03-2014-0042

Meyer, J. P. \& Allen, N. J. (1991). A Tree-component conceptualization of organizational commitment. Human Resource Management Review, 1, 61-89.

Meyer, J. P., Allen, N. J., \& Smith, C. A. (1993). Commitment to organizations and occupations: Extension and test of a three-component conceptualization. Journal of Applied Psychology, 78(4), 538-551. http://doi org/10.1037/0021-9010.78.4.538

Meyer, J. P., \& Allen, N. J. (1997). Commitment in the workplace: Theory, research, and application. Newbury Park, CA: Sage.

Mowday, R.T., Steers, R. M. \& Porter, L.W. (1979). The measurement of organizational commitment. Journal of Vocational Behavior 14, 224-247. https://doi.org/10.1016/00018791(79)90072-1

Nadler. D.A. (1981). Managing organizational change: An integrative perspective. The Journal of Applied Behavioural Science,17(2),191-211. https://doi.org/10.1177\%2F002188638101700205

Newman, L. (2001). Coping and defense: No clear distinction. American Psychologist, 56 (9), 760-761. https://doi.org/10.1037//0003-066X.56.9.760

O'Connor, C.A. (1993). Resistance: The repercussions of change. Leadership and Organization Development Journal,4(6), 30-36. https://doi.org/10.1108/01437739310145615

Oldham, M. \& Kleiner, B.H. (1990). Understanding the nature and use of defense mechanisms in organizational life. Journal of Managerial Psychology, 5(5), 1-5.

Olson, E. E. (1990). The transcendent function in organizational change. The Journal of Applied Behavioural Science. 26 (1), 69-81. https://doi.org/10.1177\%2F002188639002600107 
Piderit, S. K. (2000). Rethinking resistance and recognizing ambivalence: A multidimensional view of attitudes toward an organizational change. Academy of Management Review, 25(4), 783-794. https://doi.org/10.2307/259206

Porras, J. I., \& Robertson, P. J. (1992). Organizational development: Theory, practice and research. In M. D. Dunnette \& L. M. Hough (Eds.). Handbook of industrial and organizational psychology (pp. 719-822). Consulting Psychologists Press.

Rush, M. C., Schoel, W. A., \& Barnard, S. M. (1995). Psychological resiliency in the public sector: "Hardiness' and pressure for change. Journal of Vocational Behavior, 46(1), 17 - 39. https://psycnet.apa.org/doi/10.1006/jvbe.1995.1002

Salami, S.O. (2008) Demographic and psychological factors predicting organizational commitment among industrial workers. Anthropologist, 10(1), 31-38. https://doi.org/10.1080/09720073.2008.11891026

Schweiger, D.M. \& Denisi, A.S. (1991). Communication with employees following a merger: A longitudinal field experiment. Academy of Management Journal, 34(1), 110-135. https://doi.org/10.2307/256304

Scott, C. D. \& Jaffe, D.T. (1988). Survive and thrive in times of change. Training and Development Journal, April, 25-7.

Oreg, S. (2006). Personality, context, and resistance to organizational change. European Journal of Work and Organizational Psychology, 15 (1), 73-101. https://doi.org/10.1080/13594320500451247

Vakola, M., Tsaousis, I. \& Nikolaou, I. (2004). The role of emotional intelligence and personality variables on attitudes toward organizational change. Journal of Managerial Psychology, 19(2), 88-110. https://doi.org/10.1108/02683940410526082

Vakola, M. (2014). What's in there for me? Individual readiness to change and the perceived impact of organizational change. Leadership \& Organization Development Journal, 35(3), 195-209. https://doi.org/10.1108/LODJ-05-2012-0064

Wanous, J. P., Reichers, A.E., \& Austin, J. T. (2000). Cynicism about organizational change: Measurement, antecedent and correlates. Group \& Organizational Management, 25(2), 132-153. http://dx.doi.org/10.1177/1059601100252003

Wasiu, S. (2013). A study of causes of poor attitude to work among workers of both public and private sectors organizations in Bauchi State-Nigeria. International Journal of Academic Research in Business and Social Sciences, 3 (7), 2222-6990.

Zaltman, G. \& Duncan, R. (1977). Strategies for planned change. John Wiley \& Sons. 